\title{
Are Functional Groups Beneficial or Harmful on the Electrochemical Performance of Activated Carbon Electrodes?
}

\author{
Ziming Ding, ${ }^{1}$ Vanessa Trouillet, ${ }^{1,2}$ and Sonia Dsoke ${ }^{1,3, *, z}$ \\ ${ }^{1}$ Institute for Applied Materials (IAM), Karlsruhe Institute of Technology (KIT), D-76344 Eggenstein-Leopoldshafen, \\ Germany \\ ${ }^{2}$ Karlsruhe Nano Micro Facility (KNMF), Karlsruhe Institute of Technology (KIT), 76344 Eggenstein-Leopoldshafen, \\ Germany \\ ${ }^{3}$ Helmholtz-Institute Ulm for Electrochemical Energy Storage (HIU), D-76021 Karlsruhe, Germany
}

\begin{abstract}
It is a common opinion that activated carbon (AC) should be functional groups-free when employed as capacitor-type material in organic electrolytes. This work analyzes in detail the relationship between the electrochemical performance of modified activated carbon electrodes and the introduced functional groups in two organic electrolytes containing lithium salts: $1 \mathrm{M} \mathrm{LiPF} 6$ in EC-DMC (the commercial LP30) and 1M LiTFSI in EC-DMC. The surface functional groups (especially $\mathrm{C}=\mathrm{O}$ or $\mathrm{O}-\mathrm{C}=\mathrm{O}$ ) can induce higher capacitance to $\mathrm{AC}$ (more than 50\% increase compared to commercial unmodified AC), whereas the rate capability dramatically decreases. The appropriate amount of functional groups is helpful to expand the electrochemical stability window in LP30 (2.8-2.9 V), that is responsible for the high energy and power density. Moreover, the proper functional groups inhibit the potential shift of the AC electrode. However, a large number of functionalities can result in a high amount of irreversible redox products remaining in the pores of $\mathrm{AC}$, which leads to a faster capacitance fade respect to materials with less functional groups.

(C) The Author(s) 2019. Published by ECS. This is an open access article distributed under the terms of the Creative Commons Attribution 4.0 License (CC BY, http://creativecommons.org/licenses/by/4.0/), which permits unrestricted reuse of the work in any medium, provided the original work is properly cited. [DOI: 10.1149/2.0451906jes]

(cc)BY
\end{abstract}

Manuscript submitted January 30, 2019; revised manuscript received March 15, 2019. Published March 27, 2019.

Since neither lithium-ion batteries $(\mathrm{LIBs})^{1-3}$ nor electrochemical double layer capacitors (EDLCs) can fulfill the industrial demands of high energy, high power and long cycling stability at the same time, the concept of lithium-ion capacitors (LICs), ${ }^{4}$ which combines LIBs and EDLCs, has been emerged as a hot topic. LICs show a great prospect in many applications, e.g. mobile, communication, transportation and information technology.

Taking into account the improved high energy respect to classical EDLCs as well as the high power density, LICs based on electrodes made of activated carbon and a Li-insertion material operating in organic electrolyte have been developed by some industrial companies. ${ }^{5,6}$ As concerning the electrolyte, it is known that most of the commercial EDLCs operates in organic electrolytes based on tetraethylammonium tetrafluoroborate $\left(\mathrm{TEABF}_{4}\right)$ or triethylmethylammonium tetrafluoroborate $\left(\mathrm{TEMABF}_{4}\right)$ salts dissolved in propylene carbonate $(\mathrm{PC})$ or acetonitrile $(\mathrm{AN})$ with $\sim 1 \mathrm{~mol} / \mathrm{l}(\mathrm{M})$ concentration. ${ }^{7}$ However, in LICs the presence of a lithium salt is strictly required and a classical electrolyte used in $\mathrm{LiBs}$ (such as $1 \mathrm{M}$ $\mathrm{LiFP}_{6} / \mathrm{EC}-\mathrm{DMC}$ ) is generally employed. This electrolyte, which is a well-recognized standard in commercial batteries, has to be compatible with the capacitor type material, which is present in the hybrid device, in one or in both electrodes. ${ }^{4,8,9}$ However, the presence of carbonates may cause the formation of a passive layer (solid permeable interphase, SPI) on the extremely high carbon surface, thus limiting the EDLCs performance. ${ }^{7,10,11}$ It is recognized that, after a prolonged cycling, supercapacitors based on activated carbons and Li-salt containing electrolytes demonstrate capacity fading and resistance increase. ${ }^{12}$ One reason for this fading can be related to the decomposition of the electrolyte which can block the micropores of the carbonaceous material. ${ }^{13}$ However, the quality of the AC plays also a fundamental role on the stability. For instance, impurities such as metallic ions and heteroatoms have an essential role on the leakage current, ${ }^{14}$ on the degradation of the electrolyte, ${ }^{13}$ on resistance increase and gas evolution. Another characteristic of activated carbon is the presence of surface functional groups, which are mainly present due to the activation process applied during the material production. Functional groups are claimed as main responsible for performance degradation and ageing of AC in organic electrolytes ${ }^{14,15}$

\footnotetext{
*Electrochemical Society Member.
}

${ }^{\mathrm{z} E}$-mail: sonia.dsoke@kit.edu and, hence, it seems that the best method to attenuate the degradation is to produce materials functional groups-free. These functionalities (mainly carboxylic, lactone or phenolic groups) are thought to be harmful in organic electrolytes but beneficial in aqueous-based electrolytes, where they can provide an extra capacitance through a pseudocapacitive mechanism. ${ }^{16,17}$ However, in a very recent paper, Sheng S. Zhang proved, for the first time, that the functionalities on the surface of activated carbon contribute to the capacitance through pseudo-redox reactions in the organic electrolytes as well (1M LiPF $/$ /EC-DMC, 3:7; $1 \mathrm{M} \mathrm{TBABF} 4 /$ EC-DMC, 3:7). ${ }^{18}$ However, this report also demonstrates that the functionalities are harmful for a long cycling over a large potential window in Li-salt containing electrolyte. Functionalities can also be beneficial for inhibiting the potential shift of AC. In this context, Widmaier et al. reports about the use of functionalized activated carbon as stable reference electrode in Li-salts containing electrolytes. They studied the effect of different oxidation/reduction methods on the potential shift of $\mathrm{AC}$ and found that, when AC is strongly oxidized, the potential shift is minimized and the material can be used as an alternative quasi-reference electrode. ${ }^{19}$ However, so far, a complete electrochemical study of modified carbons with different oxidation degree in organic electrolytes is still missing. For this reason, this work aims to clarify the effect of the different functionalization/defunctionalization method on the overall performance and ageing of $\mathrm{AC}$ in organic electrolytes containing Li-salts (namely, the commercial $1 \mathrm{M} \mathrm{LiPF}_{6} / \mathrm{EC}-\mathrm{DMC}$ (LP30) and $1 \mathrm{M} \mathrm{LiTFSI/EC-DMC}(1: 1))$ and address to the question if functionalities are really harmful or can have a beneficial impact to this system.

\section{Experimental}

Preparation of active materials.-All active materials have been obtained by $\mathrm{HC}$, which is a commercial activated carbon produced by Haycarb PLC (Sri Lanka). HC is produced from coconut shell through physical activation by gasification at temperature around $1300 \mathrm{~K}$ in the presence of the suitable oxidizing gas steam.

In order to introduce the functional groups on $\mathrm{HC}$, three oxidation treatments with concentrated nitric acid $\left(\mathrm{HNO}_{3}\right)$, concentrated sulfuric acid $\left(\mathrm{H}_{2} \mathrm{SO}_{4}\right)$ and hydrogen peroxide $\left(\mathrm{H}_{2} \mathrm{O}_{2}\right)^{19,20}$ were, respectively, used. As a comparison, $\mathrm{HC}$ was also de-functionalized by flowing a mixture of Argon/Hydrogen $\left(\mathrm{Ar} / 5 \% \mathrm{H}_{2}\right)$; Pristine $\mathrm{HC}$ without any 
Table I. Abbreviations used for the activated carbon materials.

Active material

Commercial activated carbon

AC modified by $\mathrm{HNO}_{3}$

AC modified by $\mathrm{H}_{2} \mathrm{SO}_{4}$

AC modified by $\mathrm{H}_{2} \mathrm{O}_{2}$

AC reduced by $\mathrm{Ar} / \mathrm{H}_{2}$

modification was used as reference sample. The detailed preparation processes are described as following:

-Functionalization with $\mathrm{H}_{2} \mathrm{O}_{2}$ (labelled as $\mathrm{H} 2 \mathrm{O} 2-\mathrm{HC}$ ). - The $\mathrm{HC}$ powder ( $3 \mathrm{~g}$ ) was immersed in $20 \% \mathrm{wt} \%$ hydrogen peroxide solution $(30 \mathrm{ml})$. The mixture was transferred to an autoclave and stirred for $8 \mathrm{~h}$ at $80^{\circ} \mathrm{C}$. After the reaction, the residue was filtrated and washed until the $\mathrm{pH}$ of the solution reached 6 . The resulting powder was dried overnight at $120^{\circ} \mathrm{C}$ in a vacuum furnace.

-Functionalization with $\mathrm{H}_{2} \mathrm{SO}_{4}$ (labelled as $\mathrm{H} 2 \mathrm{SO} 4-\mathrm{HC}$ ).-The $\mathrm{HC}$ powder $(5 \mathrm{~g})$ was immersed in $72 \% \mathrm{wt} \% \mathrm{H}_{2} \mathrm{SO}_{4}$ solution $(50 \mathrm{ml})$. It was, then, heated and stirred for $48 \mathrm{~h}$ at $90^{\circ} \mathrm{C}$. The washing and drying processes were the same as the ones performed on $\mathrm{H} 2 \mathrm{O} 2-\mathrm{HC}$.

-Functionalization with $\mathrm{HNO}_{3}$ (labelled as $\mathrm{N}$-HC).-The functionalization with $\mathrm{HNO}_{3}$ was conducted by stirring the $\mathrm{AC}$ powder in the nitric acid solution at $95^{\circ} \mathrm{C}$ for $5 \mathrm{~h}$. For this purpose, $200 \mathrm{ml}$ of a $65 \% \mathrm{wt} \% \mathrm{HNO}_{3}$ solution was mixed with $5 \mathrm{~g}$ of $\mathrm{HC}$. The dry powder (N-HC) was obtained in the same way as for $\mathrm{H} 2 \mathrm{O} 2-\mathrm{HC}$.

-De-functionalization under Ar/ $\mathrm{H}_{2}$ flow (labelled as $\mathrm{RE}-\mathrm{HC}$ ).$\mathrm{HC}$ was de-functionalized in a high temperature furnace (Gero) by heating with $10^{\circ} \mathrm{C} / \mathrm{min}$ steps from room temperature to $700^{\circ} \mathrm{C}$ under Argon/5\%Hydrogen flow. Intermediate temperature holding steps of 15 min were conducted at $120^{\circ} \mathrm{C}$ and $500^{\circ} \mathrm{C}$ in order to ensure the full reduction process.

After functionalization and de-functionalization, the AC powders were dried under high vacuum $\left(10^{-6} \mathrm{mbar}\right)$ at $100^{\circ} \mathrm{C}$ for almost $16 \mathrm{~h}$, aiming to be ready for the physical and chemical characterization. The acronyms used for each material are resumed in Table I.

Physical and chemical characterization.- $\mathrm{N}_{2}$ adsorption/ desorption measurements were performed using Surfer porosimeter from ThermoFisher. The software "Advanced Data Processing" was employed to determine the specific surface area (SSA) and pore size distribution (PSD) of ACs. XPS was performed in a K-Alpha spectrometer (ThermoFisher Scientific, East Grinstead, UK) using a microfocused, monochromated $\mathrm{Al} \mathrm{K}_{\alpha} \mathrm{X}$-ray source (400 $\mu \mathrm{m}$ spot size). An Argon Glove box directly attached to the spectrometer enables the air free introduction of the samples in the load lock. The kinetic energy of the electrons was measured by a $180^{\circ}$ hemispherical energy analyzer operated in the constant analyzer energy mode (CAE) at $50 \mathrm{eV}$ pass energy for elemental spectra. The K-Alpha charge compensation system was employed during analysis, using electrons of $8 \mathrm{eV}$ energy, and low-energy argon ions to prevent any localized charge buildup. Data acquisition and processing using the Thermo Advantage software is described elsewhere. ${ }^{21}$ The spectra were fitted with one or more Voigt profiles (BE uncertainty: $\pm 0.2 \mathrm{eV}$ ) and Scofield sensitivity factors were applied for quantification. ${ }^{22}$ All spectra were referenced to the $\mathrm{C} 1 \mathrm{~s}$ graphitic peak at $284.4 \mathrm{eV}$ binding energy controlled by means of the well-known photoelectron peaks of $\mathrm{Cu}, \mathrm{Ag}$ and $\mathrm{Au}$ respectively. Raman measurements were performed by a Raman spectrometer (LabRam Evolution HR, Horiba Jobin Yvon) using $532 \mathrm{~nm}$ laser excitation with a power of $10 \mathrm{~mW}$. The morphology of fresh and aged samples was investigated by a scanning electron microscope (SEM, Merlin, Zeiss GmbH).
Electrode preparation and cell assembly.-The electrodes were prepared by mixing $85 \% \mathrm{wt} \%$ of active material, $5 \% \mathrm{wt} \%$ of conducting carbon black (Super P, Sigma-Aldrich) and $10 \%$ wt $\%$ of NaAlginate as a binder. Firstly, a Na-Alginate solution was prepared with $2 \% \mathrm{wt} \%$ Na-Alginate (Sigma-Aldrich) and $98 \% \mathrm{wt} \%$ mixture of water and isopropanol $(9: 1)) .{ }^{23}$ Active material and carbon black were then added to the binder solution and stirred for 5 min 800 r.p.m. with a planetary vacuum mixer (Thinky ARV-310, Germany). The obtained slurry was coated with a wet thickness of $150 \mu \mathrm{m}$ on Al-foil (thickness: $14 \mu \mathrm{m})$ and dried at room temperature overnight. Circular electrodes (average mass of active material: $1.500 \mathrm{mg}$; average thickness of electrode: $48 \mu \mathrm{m}$ ) of $12 \mathrm{~mm}$ diameter were punched out from the layer with a stamper machine (El-Cell, Germany). The electrodes were finally dried in vacuum oven at $120^{\circ} \mathrm{C}$ for 3 days and transferred in a Ar-filled Glove Box (MBraun, Germany). Swagelok-type cells with three electrodes configuration have been used for the electrochemical experiments. Glass microfiber filter (Whatman GF/A, Aldrich) was used as separator and the cell was finally filled with the electrolyte. Two electrolytes were used for the electrochemical experiments: $1 \mathrm{M}$ $\mathrm{LiPF}_{6}$ in EC: DMC $(1: 1, w t \%),(\mathrm{LP} 30, \mathrm{BASF})$ and $1 \mathrm{M}$ LiTFSI in EC: DMC $(1: 1, w t \%)$. In the case of LiTFSI-based electrolyte a $1 \%$ of $\mathrm{LiPF}_{6}$ salt was added, in order to avoid the Al-corrosion at anodic potentials. $^{24,25}$ This electrolyte is labelled as LiTFSI.

Electrochemical characterization.-Half cells (X-HC as working electrode, metallic lithium as counter and reference electrode) were employed to determine the Electrochemical Stability Window (ESW) with cyclic voltammetry measurements $(\mathrm{CV})$ according to the previously reported procedures. ${ }^{26,27}$ In detail, starting from the open circuit voltage $(\mathrm{OCV})$ the potential was increased in negative or positive direction with $0.1 \mathrm{~V}$ steps until the final potentials of $5.5 \mathrm{~V} \mathrm{vs} \mathrm{Li}^{+} / \mathrm{Li}$ and $0.5 \mathrm{~V} \mathrm{vs} \mathrm{Li}^{+} / \mathrm{Li}$ in positive and negative direction, respectively. Voltage holding test was performed in a symmetric AC//AC capacitor (Swagelok-type cells with $\mathrm{X}-\mathrm{HC}$ as working and counter electrode, metallic lithium as reference electrode) by keeping the cell voltage at $1.3 \mathrm{~V}$ for $300 \mathrm{~h}$. Every $10 \mathrm{~h}$ the voltage holding was interrupted and the electrochemical performance were evaluated by galvanostatic cycles (at $0.5 \mathrm{~A} \mathrm{~g} \mathrm{~g}^{-1}$ in the safe voltage window of $1 \mathrm{~V}$ ) and Electrochemical Impedance Spectroscopy (EIS). The symmetric cells were also subjected to 10,000 repeated galvanostatic cycles performed between $0-2 \mathrm{~V}$ at the current of $1 \mathrm{~A} \mathrm{~g}^{-1}$. EIS and CVs were recorded on fresh and cycled electrodes. EIS was performed at OCV in the frequency range $500 \mathrm{kHz}-10 \mathrm{mHz}$. CVs were recorded at $10 \mathrm{mV} \mathrm{s}^{-1}$ in the cell voltage $0-2 \mathrm{~V}$. Rate capability test was conducted in the restricted cell voltage $0-1 \mathrm{~V}$ at currents of $0.1,0.5,1.0,2.0,5.0,10.0$ and $0.1 \mathrm{~mA} \mathrm{~g}^{-1}$. The restricted voltage was chosen in order to evaluate only the rate performance, while avoiding any degradation due to the electrolyte decomposition. The specific current was calculated by considering the active material mass of both electrodes. The cells were placed in a climate chamber at $25^{\circ} \mathrm{C}$ and the electrochemical measurements were performed with a VMP3 multi-channel potentiostat/galvanostat (Bio-logic Science Instrument, France), equipped with an EC-Lab software.

\section{Results and Discussion}

Textural and chemical characterization of activated carbon materials.-Modified and unmodified activated carbons were firstly studied by means of $\mathrm{N}_{2}$ adsorption/desorption and XPS.

According to the IUPAC ${ }^{28}$ notation, the nitrogen sorption isotherm diagrams of all X-HC powders show the typical Type I behavior, which indicates that all AC materials are predominantly microporous. From the hysteresis between adsorption and desorption, a narrow slit pore structure can be deduced for all samples. These data suggest that the modification processes have no significant influence on the pore structure of carbons. The reduction treatment of $\mathrm{H}_{2}$ does not substantially changes the pore volume respect to the non-modified AC (HC: $0.845 \mathrm{~cm}^{3} \mathrm{~g}^{-1}$ ), while after all oxidation treatments the pore 


\begin{tabular}{lll}
$\begin{array}{l}\text { Table II. BET specific surface area and pore volume of } \\
\text { powders. }\end{array}$ & \\
& $\mathrm{S}_{\mathrm{BET}}\left(\mathrm{m}^{2} \mathrm{~g}^{-1}\right)$ & Pore Volume $\left(\mathrm{cm}^{3} \mathrm{~g}^{-1}\right)$ \\
\hline $\mathrm{HC}$ & 1677 & 0.845 \\
$\mathrm{RE}-\mathrm{HC}$ & 1714.9 & 0.851 \\
$\mathrm{~N}-\mathrm{HC}$ & 1454.6 & 0.737 \\
$\mathrm{H} 2 \mathrm{SO} 4-\mathrm{HC}$ & 1560.3 & 0.803 \\
$\mathrm{H} 2 \mathrm{O} 2-\mathrm{HC}$ & 1594 & 0.817
\end{tabular}

volume becomes smaller, as also shown in Table II. This suggests that the functionalities are partially placed inside or at the entrance of the micropores, thus reducing the available volume. The trend of the specific surface area (calculated from the Brauner-Emmett-Teller model $(\mathrm{BET}))$ is the same as for the pore volume (Table II). For instance, oxidation with nitric acid confers the smallest BET area $\left(1454.6 \mathrm{~m}^{2} \mathrm{~g}^{-1}\right)$ among the samples. One important factor to consider is that the treatment with $\mathrm{HNO}_{3}$ introduces various oxygen functional groups onto the carbon surface, which leads to an increase of the mass. This could contribute to the reduction of pore volume and specific surface area. On the other side, the $\mathrm{H}_{2}$ flow removes the functional groups from the surface of RE-HC, which leads to an increased surface area.

According to previous studies, it is known that not all micropores contribute to the capacitance of EDLCs. ${ }^{29}$ When the pore size is smaller than the solvated electrolyte ions, it is difficult for the ions to freely penetrate into the pores and to be adsorbed on the inner pore surface. The pore size distribution (PSD) of all carbon powders is shown in Figure 1b. N-HC powder shows bigger pore size than other samples, with size centered on $1.4 \mathrm{~nm}$. The other samples show a similar PSD with pore diameters centered on $1.2 \mathrm{~nm}$. This size cannot be an inhibition for the ion penetration, since all ions present in the electrolyte have smaller dimensions than the pores: Li-ion has size of $\sim 0.4 \mathrm{~nm}$ (solvated) and $0.08 \mathrm{~nm}$ (naked)), $\mathrm{PF}_{6}{ }^{-}$has a size of $0.245 \mathrm{~nm}$ (solvated) and TFSI $^{-}$of $0.29 \mathrm{~nm}^{*} 0.79 \mathrm{~nm}$ (solvated).

XPS analysis reveals the presence of oxygen containing groups at the surface of all investigated samples. The as received activated carbon has an oxygen content of $4.9 \%$. The oxygen content increases to $6.8 \%, 8.0 \%$ and $16.0 \%$ for the samples treated with $\mathrm{H}_{2} \mathrm{O}_{2}, \mathrm{H}_{2} \mathrm{SO}_{4}$ and $\mathrm{HNO}_{3}$, respectively. On the other side, the hydrogen reduction treatment effectively reduces the oxygen amount to $1.1 \%$.

The series of resolved $\mathrm{C}$ 1s XP spectra of different AC powders are depicted in Figure 2a. The quantitative analysis is presented in Table III. C 1s spectra of all carbons show a main peak at $284.4 \mathrm{eV}$ typical for $\mathrm{sp}^{2}$ - hybridized carbon and a broad peak at $\sim 290.5 \mathrm{eV}$, which is attributed to the characteristic $\pi \rightarrow \pi^{*}$ shake-up satellite for carbon in aromatic compounds. The peak at $284.4 \mathrm{eV}$ shows a pronounced asymmetric shape to higher binding energies due to quantum mechanical coupling of core electrons with conduction electrons. ${ }^{30}$ This graphitic character is also confirmed by the Raman spectroscopy (Figure $2 \mathrm{c}$ ). The ratio of $\mathrm{I}_{\mathrm{D}} / \mathrm{I}_{\mathrm{G}}$, which gives information about the graphitization degree, is between 3.99 and 4.45 (Table III). Among all samples, a very small divergence to the ratio of HC is observed, which proves that the oxidation and reduction treatments has only a marginal effect on the carbon ordering structure and the primarily nanocrystalline graphite structure is effectively maintained after all treatments. Nevertheless, additional distinct peaks at $286.5 \mathrm{eV}$ and $288.3 \mathrm{eV}$ arise in the $\mathrm{C} 1 \mathrm{~s}$ XP spectra of $\mathrm{H} 2 \mathrm{O} 2-\mathrm{HC}$ and $\mathrm{N}-\mathrm{HC}$, and can be assigned to $\mathrm{C}-\mathrm{O}$ and $\mathrm{C}=\mathrm{O}$ groups, ${ }^{31,32}$ respectively, whereas this last peak shifts to $288.9 \mathrm{eV}$ for $\mathrm{H} 2 \mathrm{SO} 4-\mathrm{HC}$ and can be attributed to carboxylic groups. Their intensities depend on the different oxidation treatments. The concentration of $\mathrm{C}-\mathrm{O}$ is higher than that of $\mathrm{C}=\mathrm{O}$ and $\mathrm{O}-\mathrm{C}=\mathrm{O}$ groups for oxidized samples. The ratios of the concentrations of oxygen containing groups and $\mathrm{sp}^{2}$ carbon are depicted in Figure $2 \mathrm{~b}$. N-HC has the highest ratios for $\mathrm{C}-\mathrm{O} / \mathrm{sp}^{2}$ and $(\mathrm{O}-\mathrm{C}=\mathrm{O}$, $\mathrm{C}=\mathrm{O}) / \mathrm{sp}^{2}$ and is, therefore, the most oxidized sample of the series. The other two oxidized samples show a bigger ratio of $\mathrm{C}-\mathrm{O} / \mathrm{sp}^{2}$ than that of $(\mathrm{O}-\mathrm{C}=\mathrm{O}, \mathrm{C}=\mathrm{O}) / \mathrm{sp}^{2}$, which means that $\mathrm{AC}$ experienced a mild oxidation process.

The reduced sample, RE-HC, contains a very small amount of $\mathrm{C}-\mathrm{O}$ and no further oxidized component, like expected. The atomic composition data indicate that, the highest amount of $\mathrm{sp}^{2}$ carbon in RE$\mathrm{HC}(89$ at\%) proves the possibility of the presence of higher reactive sites $^{33}$ in this sample respect to the others, while the appearance of $\mathrm{sp}^{3}$ carbon in $\mathrm{HC}, \mathrm{H} 2 \mathrm{O} 2-\mathrm{HC}, \mathrm{H} 2 \mathrm{SO} 4-\mathrm{HC}$ and $\mathrm{N}-\mathrm{HC}$ samples suggests the presence of more inactive sites.

The XPS measurements prove the successful introduction and removal of functional groups, which can be tuned by using different reagents.

Electrochemical properties of AC-modified materials.-The ESW for each AC electrode in LP30 was calculated considering the criterions of $\mathrm{Xu}$ et al. ${ }^{26}$ and Weingarth et al., ${ }^{27}$ When polarized in the cathodic direction, $\mathrm{HC}$ and other oxidized $\mathrm{HC}$ show similar potential limit to $1.5 \mathrm{~V}$ vs. $\mathrm{Li}^{+} / \mathrm{Li}$, whereas $\mathrm{RE}-\mathrm{HC}$ has the smallest ESW with a cathodic limit of $1.8 \mathrm{~V} \mathrm{vs}$. $\mathrm{Li}^{+} / \mathrm{Li}$. When subjected to anodic polarization, $\mathrm{HC}, \mathrm{H} 2 \mathrm{SO} 4-\mathrm{HC}$ and $\mathrm{H} 2 \mathrm{O} 2-\mathrm{HC}$ electrodes have similar stability limit until $4.4 \mathrm{~V}$ vs. $\mathrm{Li}^{+} / \mathrm{Li}(\mathrm{HC})$ or $4.3 \mathrm{~V}$ vs. $\mathrm{Li}^{+} / \mathrm{Li}(\mathrm{H} 2 \mathrm{SO} 4-\mathrm{HC}$ and $\mathrm{H} 2 \mathrm{O} 2-\mathrm{HC}$ ) (Table IV). On the contrary, N-HC and RE-HC display a lower anodic limit of $3.9 \mathrm{~V}$ and $4 \mathrm{~V}$ for $\mathrm{N}-\mathrm{HC}$ and for RE-HC, respectively. The ESW of RE-HC material in LP30 is the smallest overall, which suggests that some of the functional groups can contribute to
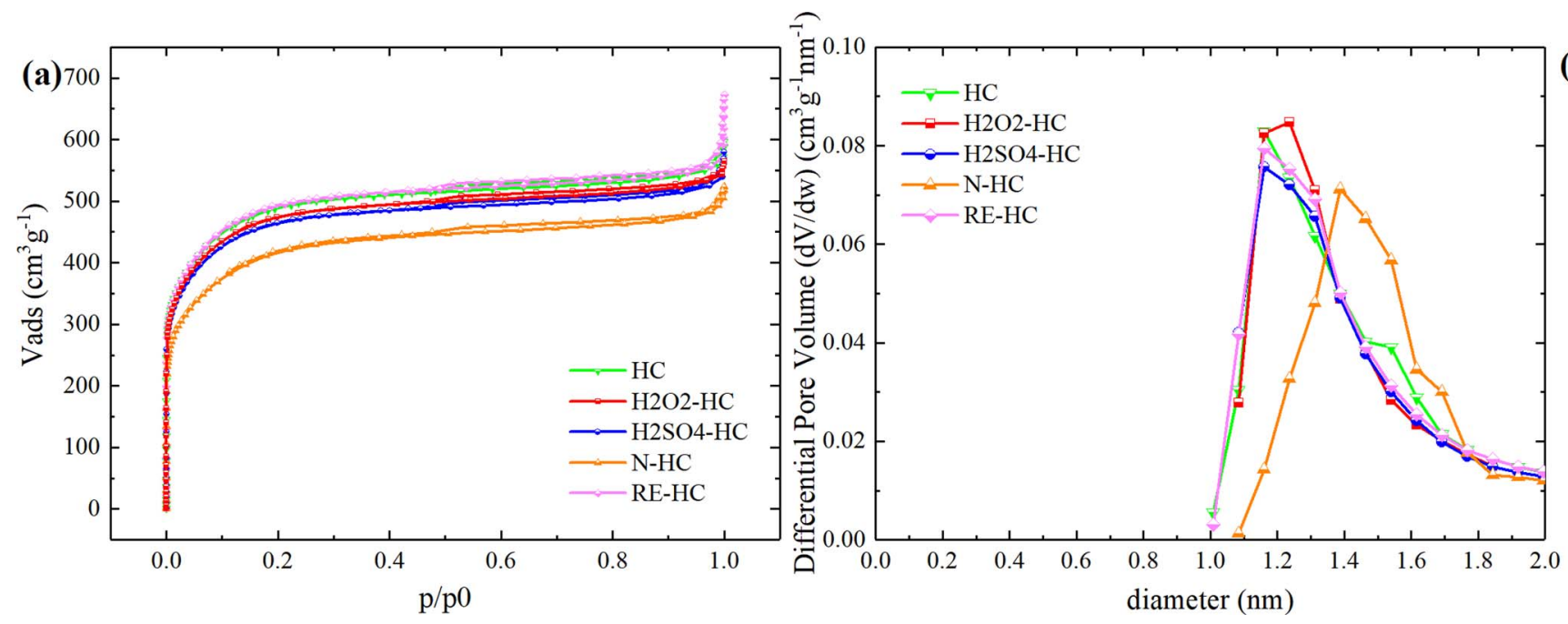

(b)

Figure 1. $\mathrm{N}_{2}$ adsorption and desorption isotherm diagrams (a) and pore size distribution (PSD) (b) of different AC powders. 
(a)

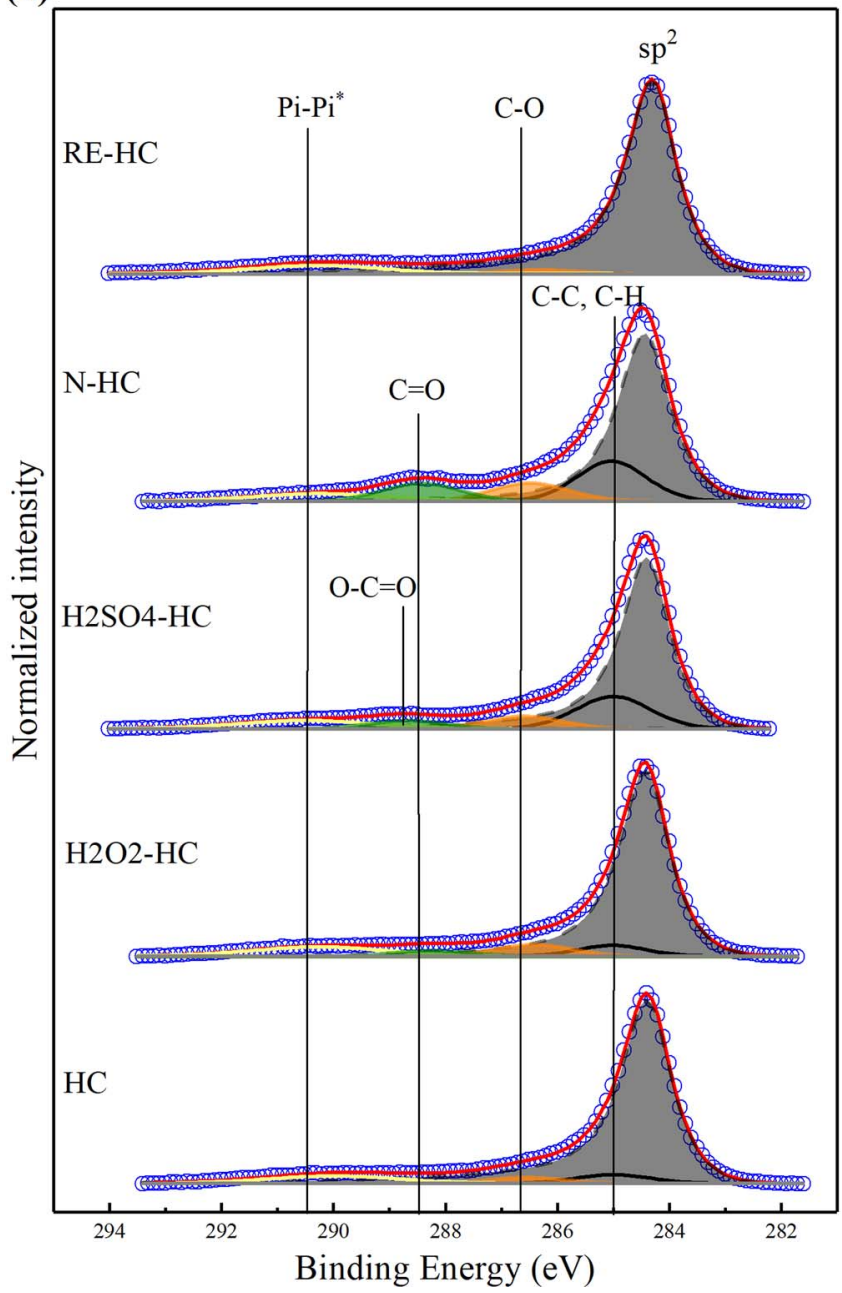

(b)

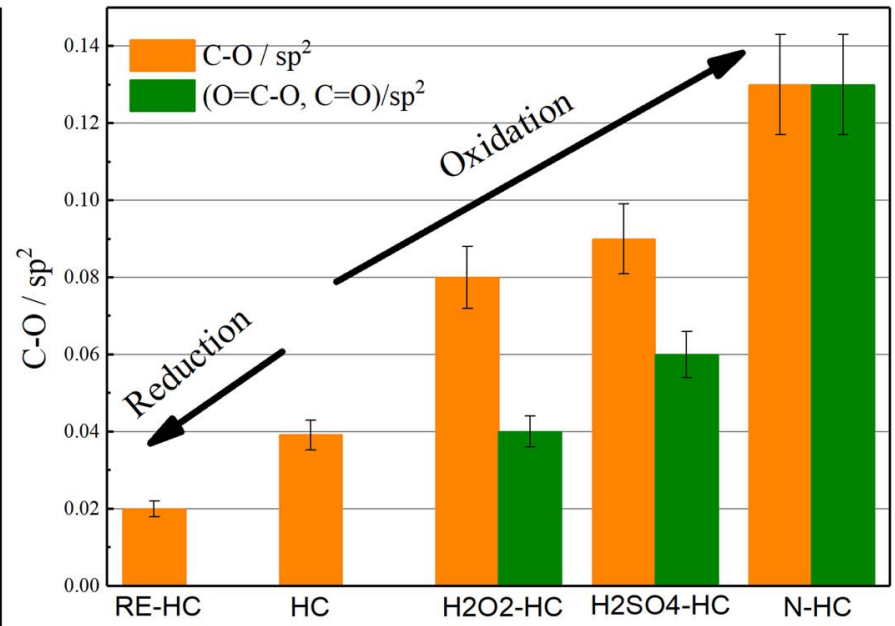

(c)

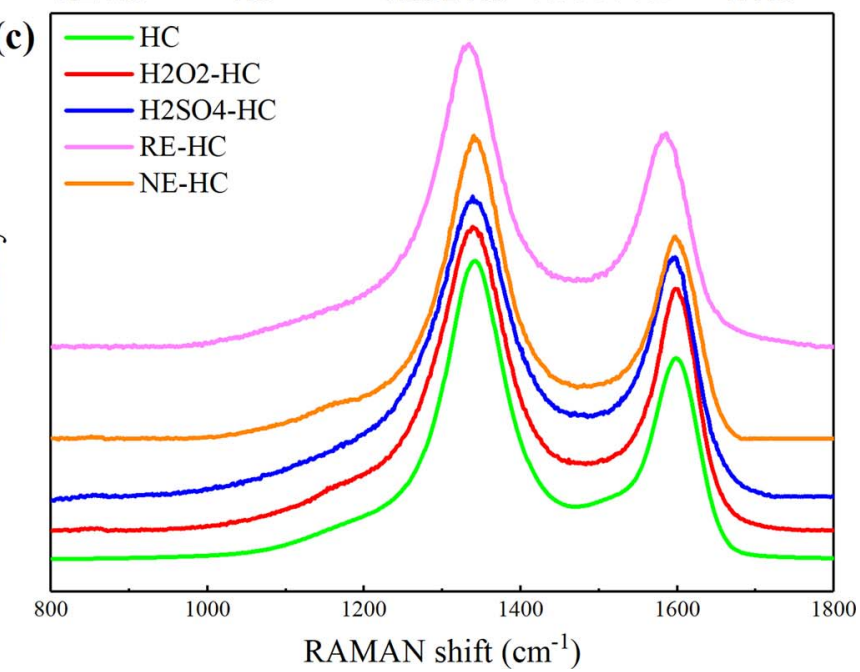

Figure 2. C 1s XP spectra of different carbon powder samples. All spectra are normalized to the maximum of intensity (a); Ratios of XPS concentrations of oxygen containing groups and $\mathrm{sp}^{2}$ carbon for different carbon powder samples (b); RAMAN spectra of different carbons (c).

Table III. Quantitative analysis of the C 1s XP spectra of different AC powders and total oxygen content (above); Raman data of the carbon materials (below). The Raman spectra were fitted with Gauss-Lorentzian peaks for D-mode and G-mode, respectively.

\begin{tabular}{|c|c|c|c|c|c|}
\hline & RE-HC & $\mathrm{HC}$ & $\mathrm{H} 2 \mathrm{O} 2-\mathrm{HC}$ & $\mathrm{H} 2 \mathrm{SO} 4-\mathrm{HC}$ & $\mathrm{N}-\mathrm{HC}$ \\
\hline $\mathrm{sp}^{2} 284.4 \mathrm{eV}($ at $\%)$ & 89 & 80.5 & 71.9 & 61.6 & 51.1 \\
\hline C-O, C-O-C $286.5 \mathrm{eV}$ (at\%) & 2.2 & 3.2 & 5.7 & 5.8 & 6.9 \\
\hline $\mathrm{O}-\mathrm{C}=\mathrm{O} 288.9 \mathrm{eV}(\mathrm{at} \%)$ & - & - & - & 3.8 & - \\
\hline$\pi-\pi^{*}$ transitions $290-290.5 \mathrm{eV}($ at $\%)$ & 7.6 & 6.7 & 7.9 & 6.6 & 5.0 \\
\hline O total $(\mathrm{at} \%)$ & 1.1 & 4.9 & 6.8 & 8.0 & 16.0 \\
\hline $\mathrm{I}_{\mathrm{D}} / \mathrm{I}_{\mathrm{G}}$ & 3.61 & 3.99 & 3.75 & 4.34 & 4.45 \\
\hline
\end{tabular}

Table IV. ESWs of AC electrodes in LP30.

\begin{tabular}{llll} 
& Cathodic polarization vs. $\mathrm{Li}^{+} / \mathrm{Li}$ & Anodic polarization vs. $\mathrm{Li}^{+} / \mathrm{Li}$ & $\mathrm{Operating} \mathrm{window}$ \\
\hline $\mathrm{RE}-\mathrm{HC}$ & $1.8 \mathrm{~V}$ & $4 \mathrm{~V}$ & $2.2 \mathrm{~V}$ \\
$\mathrm{HC}$ & $1.5 \mathrm{~V}$ & $4.4 \mathrm{~V}$ & $2.9 \mathrm{~V}$ \\
$\mathrm{H} 2 \mathrm{O} 2-\mathrm{HC}$ & $1.5 \mathrm{~V}$ & $4.3 \mathrm{~V}$ & $2.8 \mathrm{~V}$ \\
$\mathrm{H} 2 \mathrm{SO} 4-\mathrm{HC}$ & $1.4 \mathrm{~V}$ & $4.3 \mathrm{~V}$ & $2.9 \mathrm{~V}$ \\
$\mathrm{~N}-\mathrm{HC}$ & $1.5 \mathrm{~V}$ & $3.9 \mathrm{~V}$ & $2.4 \mathrm{~V}$
\end{tabular}




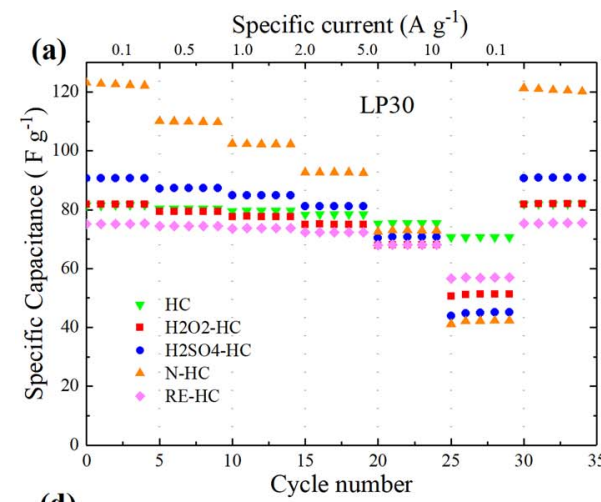

(b)

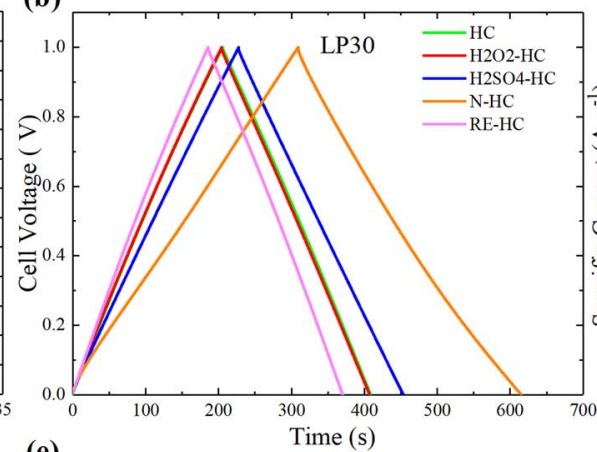

(c)
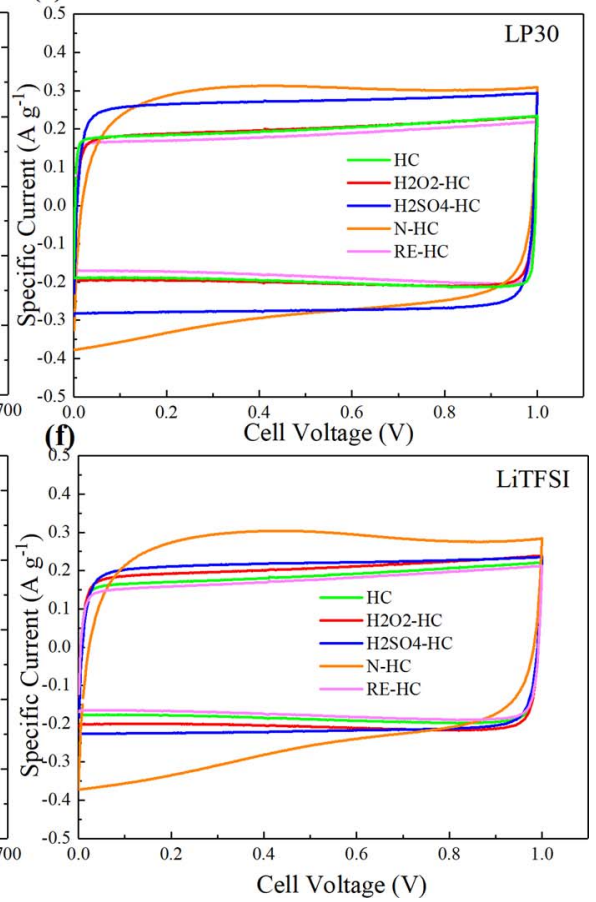

Figure 3. Specific capacitance at various currents of symmetric AC//AC devices in LP30 and LiTFSI/EC-DMC electrolytes (a, d); Galvanostatic charge and discharge profiles recorded at $0.1 \mathrm{~A} \mathrm{~g}^{-1}$ (b, e); Cycling voltammetry profiles recorded at $10 \mathrm{mV} \mathrm{s}^{-1}$ (c, f).

the wider ESW. The presence of more reactive sites, introduced by the $\mathrm{H}_{2}$ reduction treatment, can be responsible for the narrower ESW of RE-HC. Differently, the narrow ESW of the N-HC oxidized sample can be due to the substantial higher amount of the $\mathrm{C}=\mathrm{O}$ groups respect to the other samples. On the other side, it is well known that LiTFSI corrodes the Al-current collectors at potential above $3.8 \mathrm{~V} .{ }^{34,35}$ Hence, the electrochemical stability windows of the different AC electrodes in LiTFSI-based electrolyte are not presented in this work.

In order to study the effect of the carbon modification on the capacitive properties, galvanostatic cycling were conducted in a very small voltage range, where any other side effect due to electrolyte decomposition or current collector corrosion (in the case of LiTFSI-based electrolyte) are completely avoided.

As presented in Figures $3 \mathrm{~b}$ and $3 \mathrm{e}$, linear and symmetrical charge and discharge branches can be observed for all AC samples, indicating good capacitive behavior and excellent coulombic and energy efficiencies. At low specific current $\left(0.1 \mathrm{~A} \mathrm{~g}^{-1}\right) \mathrm{N}-\mathrm{HC}$ shows superior capacitance respect to the pristine $\mathrm{HC}$ in both electrolytes, with $120 \mathrm{~F} \mathrm{~g}^{-1}$ against the $80 \mathrm{~F} \mathrm{~g}^{-1}$ of the unmodified material. The other two oxidized samples show, as well, higher specific capacitance. On the contrary, the reduction process results in a slight decrease of capacitance. Combing these results with the $\mathrm{S}_{\mathrm{BET}}$, we can observe that oxidized samples (N-HC, H2O2-HC and H2SO4-HC) have lower specific surface area but higher specific capacitance respect to the unmodified carbon HC. Furthermore, the reduced sample (RE-HC) possesses relatively higher specific surface area but lower specific capacitance compared to pristine HC. However, this observation is somehow in contrast with the accepted theory that the capacitance of activated carbon is directly dependent to the surface area. ${ }^{7}$ Since no redox features can be recognized from the galvanostatic profiles (the profiles are linear, without any plateau), the only source of additional capacitance can be related to pseudocapacitive redox reactions on the functional groups of AC. The pseudocapacitive contribution can be better detected from the cyclic voltammetry (shown in Figures $3 \mathrm{c}$ and $3 \mathrm{f}$ ): a very broad hump appears in the profile of N-HC. On the contrary, all other curves show a typical box-type profile, without any apparent evidence of faradaic reactions. At low current, the capacitance is not dependent on the electrolyte used. This fact proves that the anions $\left(\mathrm{PF}_{6}{ }^{-}\right.$and $\left.\mathrm{TFSI}^{-}\right)$do not take part in the pseudoredox reactions. In terms of rate capability, all modified carbons display low performance than the commercial unmodified one. At $10 \mathrm{~A} \mathrm{~g}^{-1}$ the N-HC delivers the lowest capacitance among the carbons in both electrolytes. This behavior can be mainly attributed to the limitation of redox kinetics of the functional groups and hindered diffusion of the ions inside the pores.

Influence of functional groups on potential shift and stability.As already reported by Widmeir et al., ${ }^{19}$ the surface functionality can strongly affect the initial OCV and the potential shift of the AC electrode with time. The big amount of electron-withdrawing oxygen groups explains the high initial OCV of N-HC, while the lower OCV of RE-HC is due to the elimination of the oxygen functionalities (Table V). The static OCV of all materials was measured versus a metallic Li reference electrode for 480h in both LP30 and LiTFSIbased electrolytes. During this relaxation time, the potential of RE$\mathrm{HC}$ continuously rises up to $0.15 \mathrm{~V}$ vs. $\mathrm{E}_{\text {initial }}$ in both electrolytes. The unmodified $\mathrm{HC}$ also displays a continuous potential shift, more pronounced in LP30, but still much lower respect to the one observed in RE-HC. A very particular behavior is shown by the N-HC electrode. Its potential considerably shifts in both electrolytes, however, the shift follows different directions: it reaches more positive potentials in $\mathrm{LiPF}_{6}$ and more negative potentials in LiTFSI salt. This suggests the involvement and the interaction of the lithium salt with the functional groups of N-HC. The two salts can be responsible for the different types of

Table $\mathrm{V}$. Initial potential of different $\mathrm{AC}$ electrodes vs. $\mathrm{Li}^{+} / \mathrm{Li}$ in both electrolytes.

RE-HC HC H2O2-HC H2SO4-HC N-HC

$\begin{array}{lllll}\text { Reduction } & & \text { Oxidation } \\ 2.982 \mathrm{~V} & 3.027 \mathrm{~V} & 3.086 \mathrm{~V} & 3.149 \mathrm{~V} & 3.232 \mathrm{~V}\end{array}$

$\begin{array}{llllll}\text { LP30 } & 2.982 \mathrm{~V} & 3.027 \mathrm{~V} & 3.086 \mathrm{~V} & 3.149 \mathrm{~V} & 3.232 \mathrm{~V} \\ \text { LiTFSI/EC-DMC } & 2.982 \mathrm{~V} & 3.058 \mathrm{~V} & 3.064 \mathrm{~V} & 3.115 \mathrm{~V} & 3.311 \mathrm{~V}\end{array}$



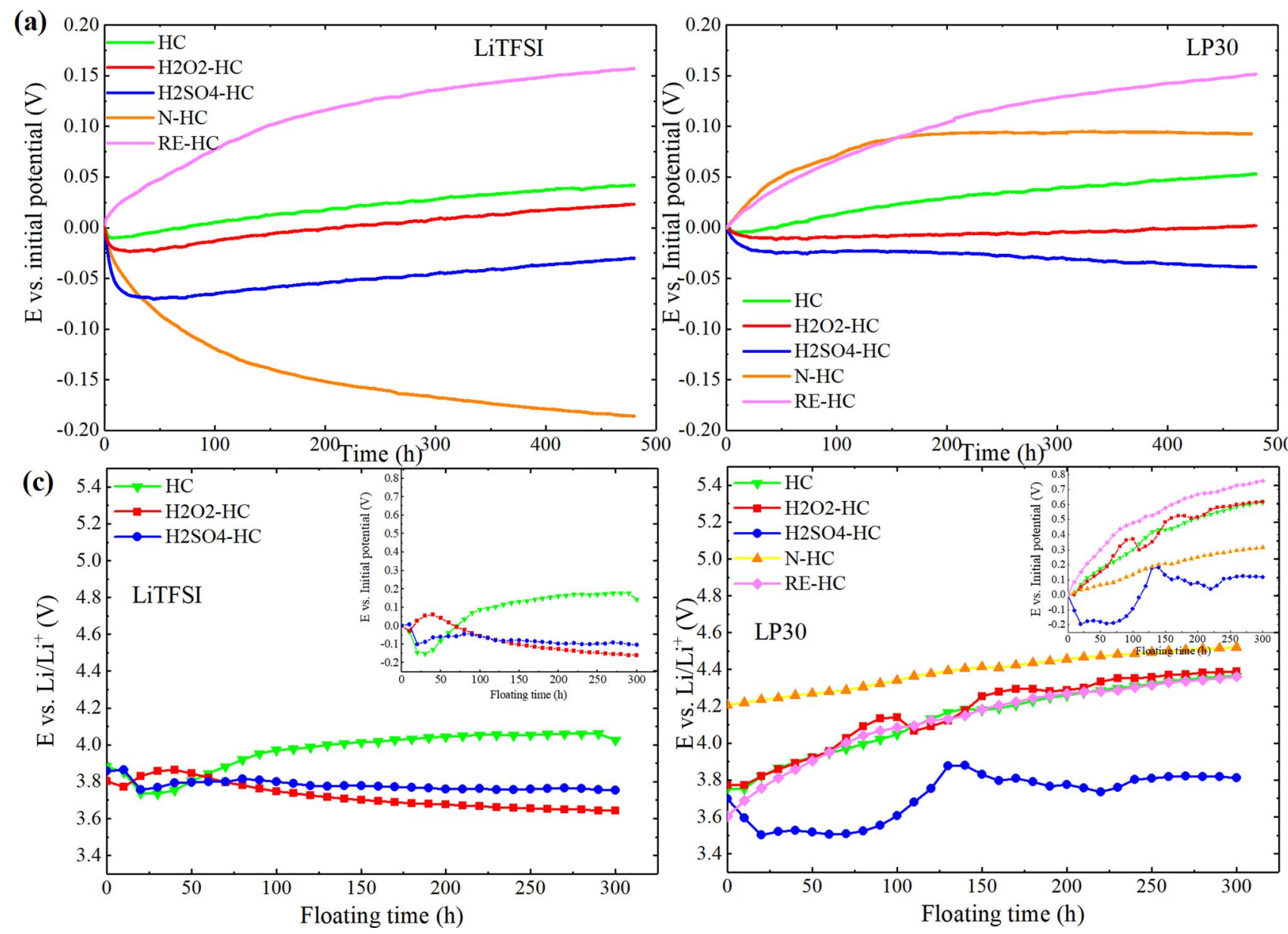

(d)

Figure 4. Potential shift of different AC electrodes in static mode (a LiTFSI \& b LP30) and dynamic mode (positive electrode) (c LiTFSI \& d LP30).

solid permeable interphase (SPI), which spontaneously forms on the surface of the material. ${ }^{10,11}$ Overall, the potential of $\mathrm{H} 2 \mathrm{O} 2-\mathrm{HC}$ is the most stable in both electrolytes.

Nevertheless, even if the behavior under static condition is very important if the activated carbon has to be used as "quasi-reference electrode" ${ }^{19}$ it is crucial to observe the shift also under dynamic conditions (i.e. polarization). Indeed, in a full cell, if during cycling one of the electrodes is subjected to potential shift, the electrochemical stability window can be crossed, having impact on the stability of the entire cell. ${ }^{12,36}$ Here, the symmetric AC//AC cells were kept for $300 \mathrm{~h}$ at the floating voltage of $1.3 \mathrm{~V}$. At this voltage, all electrode materials are (at the beginning of the floating tests) still inside the "safe" potential window. Such a low cell voltage was intentionally chosen in order to observe if there is any additional shift under polarization conditions and identify possible electrode degradations, without the interference of additional side reactions. Every 10 hours, the floating was interrupted and the performance were evaluated by mean of galvanostatic cycles and EIS. Figures $4 \mathrm{c}$ and $4 \mathrm{~d}$ report the potential drift of the positive AC electrodes during the holding time in LP30 and LiTFSI-based electrolytes. In LP30, except for the H2SO4-HC electrode, all positive electrodes cross their upper stability limit after a relatively short time (reference to Table IV). In particular, N-HC crosses its limit already during the first 10 hours of floating. However, this material has the smallest shift $\left(4.25-4.55 \mathrm{~V}\right.$ vs. $\left.\mathrm{Li}^{+} / \mathrm{Li}\right)$ compared to the other samples. The potential of RE-HC crosses its upper limit after $84 \mathrm{~h}$ of floating and displays the largest shift (3.75-4.4 V vs. $\mathrm{Li}^{+} / \mathrm{Li}$ ) among all samples. Furthermore, it is remarkable that in LP30 the charge/discharge profiles retain their symmetry after $300 \mathrm{~h}$ of floating time, proving that the good columbic efficiency is maintained (Figures 5a, 5b and 5c). The capacitance related to RE-HC, HC and $\mathrm{H} 2 \mathrm{O} 2-\mathrm{HC}$ samples increase at the beginning of the floating measurement, meaning that some initial activation process occurs. After that, the capacitances remain stable until the end of the experiment. In the case of N-HC, the capacitance first slightly increases and then start to smoothly decrease after $175 \mathrm{~h}$ of floating. In this context, the large number of functional groups introduce not only pseudocapacitance, but also the irreversible redox reactions, as also observed by Sheng S. Zhang. ${ }^{18}$ Differently from the other samples, the discharge capacitance of $\mathrm{H} 2 \mathrm{SO} 4-\mathrm{HC}$ is relatively stable. However, its efficiency decreases, indicating that some irreversible reactions take place.

In LiTFSI-based electrolyte, in which only three exemplary of materials were investigated, the situation is completely different. The potentials are much more stable compared to LP30 and no strong shift is observed (Figure 4d). However, the galvanostatic profiles dramatically change after $300 \mathrm{~h}$ of potential holding (Figures 5e and 5f). The strong asymmetry between the positive and negative electrodes suggests that the capacitance of the negative electrode dramatically decrease, thus limiting the capacitance of the whole device. One has to keep in mind that even if the potentials of positive electrodes are not dramatically increasing, the $\mathrm{TFSI}^{-}$anion leads to a severe corrosion of the Al-current collector above $3.8 \mathrm{~V} \mathrm{vs} . \mathrm{Li}^{+} / \mathrm{Li}$, which is reached during the floating time; the presence of $1 \%$ of $\mathrm{LiPF}_{6}$ in the electrolyte may not be enough to effectively passivate the current collector. The fact that the negative electrode is more affected by the ageing can be explained in this way: the degradation products formed at the positive electrode (promoted by $\mathrm{TFSI}^{-}$and functional groups) are shuttling to the surface of the negative one, where they are reduced, thus blocking the inner and deeper pores of the activated carbon and decreasing the capacitance (Figure 5d). H2SO4-HC shows higher iRdrop than that HC and H2O2-HC- based cells (Figure 5f). This can be 

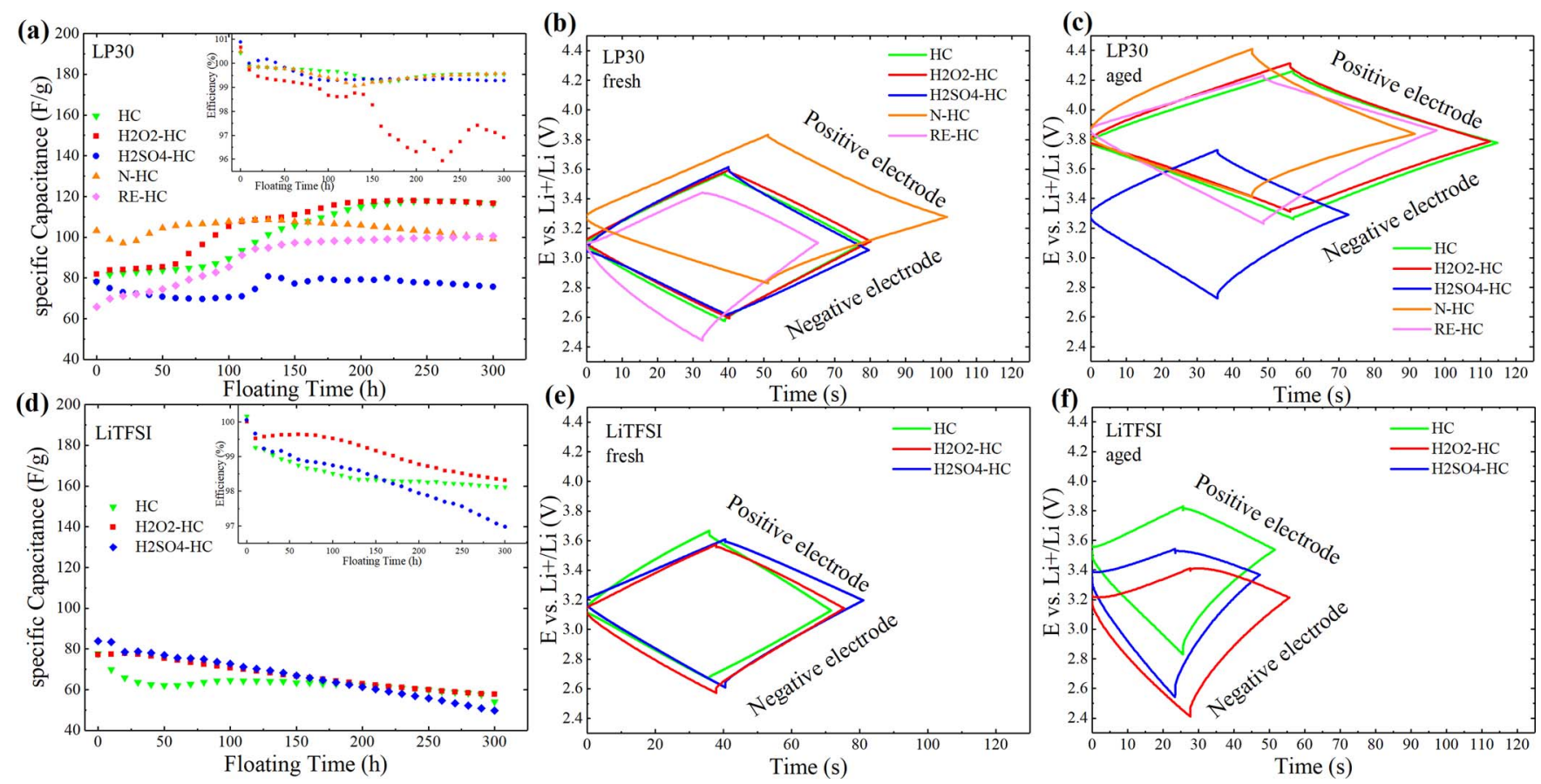

Figure 5. Evolution of specific capacitance and voltage profiles of different ACs in both electrolytes during ageing floating measurements. (a - c: LP30); (d - f: LiTFSI).
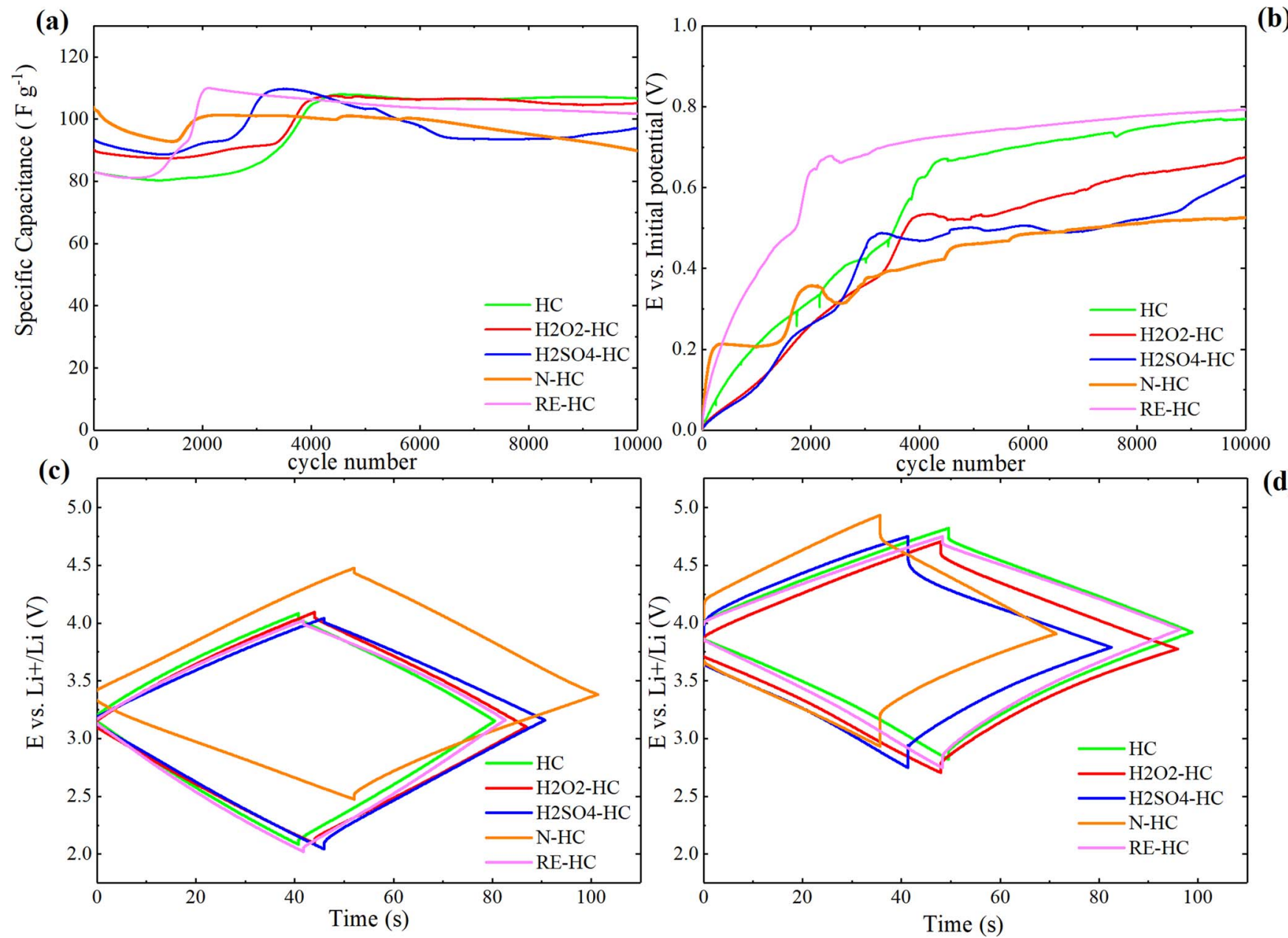

(d)

Figure 6. Evolution of specific capacitance (a), potential shift (b) and voltage profiles of the $10,000^{\text {th }}$ cycle for different ACs in LP30 electrolyte at the current of $1 \mathrm{Ag}^{-1}$ between $0-2 \mathrm{~V}$ (c: first cycle; d: last cycle). 

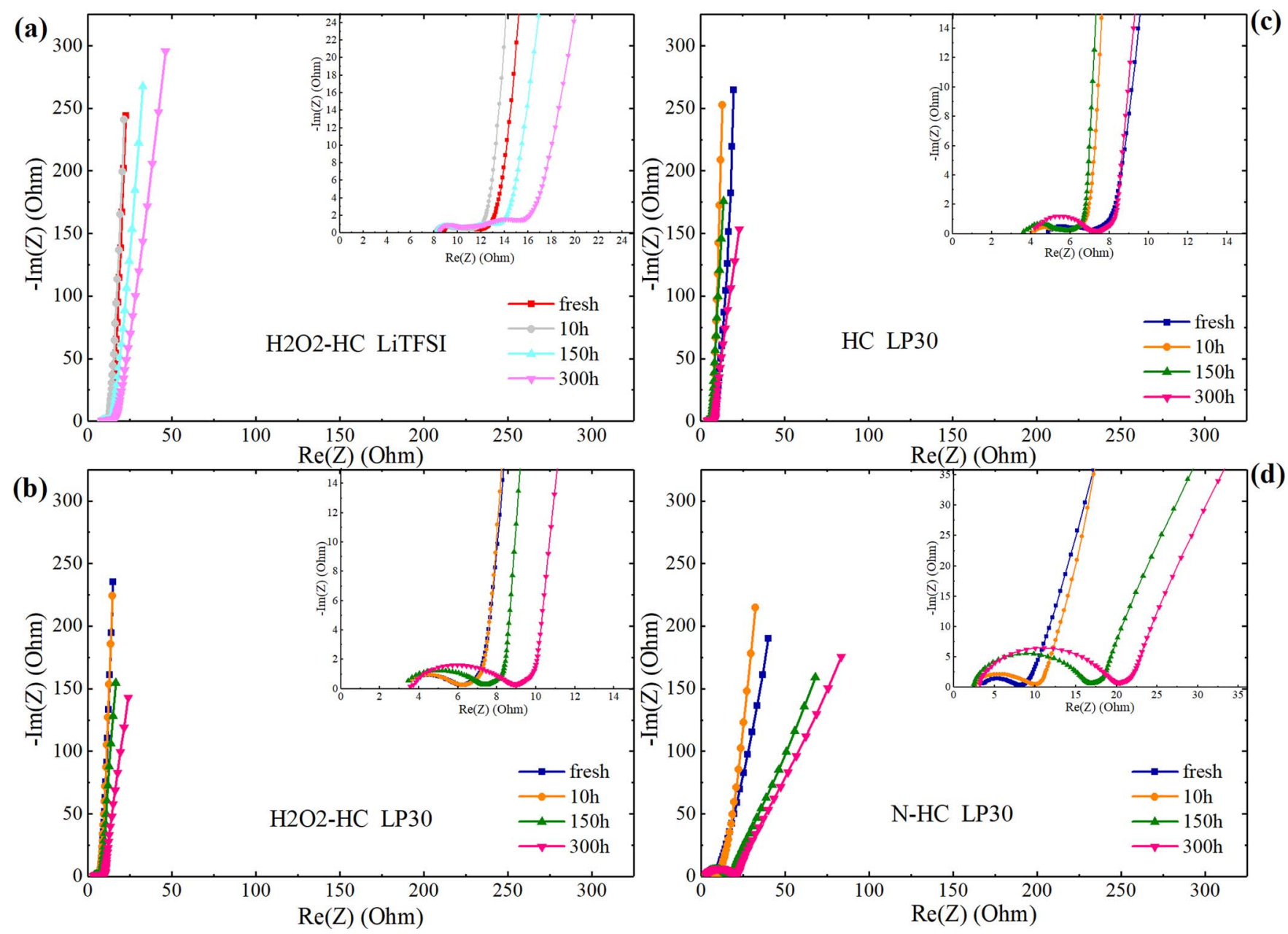

Figure 7. The evolution of electrochemical impedance spectra of the full cells made of different AC electrodes in LiTFSI (a) and in LP30 (b-d) with floating time. $\mathrm{E}=0 \mathrm{~V}$.

correlated to the higher amount of functional groups $(\mathrm{C}=\mathrm{O}, \mathrm{O}-\mathrm{C}=\mathrm{O})$ in this material respect to the other two carbons.

From these results it is clear that the polarization has an important role on the potential shift with time. Indeed, in static mode, the OCV is subjected to a smaller shift. The shift can be promoted by the side reactions occurring on the surface of the carbon at higher potential. Similar to what obtained in the static mode (Figure 4b), in LP30, the stability of RE-HC is the worst among all samples. N-HC shows a stabilization of the potential after only $25 \mathrm{~h}$, while the potential of $\mathrm{H} 2 \mathrm{SO} 4-\mathrm{HC}$ remains the lowest one during the whole experiment time. In general, the stability of oxidized carbons seems better than the reduced one (RE-HC). As mentioned before, this could be related to fewer reactive sites on the surface of oxidized carbon than that of the reduced one (Table III). The presence of $\mathrm{sp}^{3}$ carbon decreases the chance of the reaction between electrolyte and carbon. The potential shifts of the oxidized samples (H2O2-HC and H2SO4-HC) in LiTFSI-based electrolyte are clearly smaller than that of pristine HC (Figure 4d). The potential of $\mathrm{H} 2 \mathrm{O} 2-\mathrm{HC}$ is the most stable one in LiTFSI electrolyte, also similarly to what obtained in the static mode.

At last, the behavior of the various electrodes was also investigated under real dynamic conditions. In this purpose, the cells were subjected to subsequent 10,000 cycles at the current $1 \mathrm{~A} \mathrm{~g}^{-1}$ between $0-2 \mathrm{~V}$.

The potential shift of the positive electrode is similar to the one observed during the floating test (Figure 6b). However, differently than in the floating tests, the iR-drop of oxidized samples increase more significantly, whereas the pristine and reduced carbons perform better (Figures $6 \mathrm{c}$ and $6 \mathrm{~d}$ ). This implicates that the larger operating voltage has impact on the decomposition reactions and production of passive product on the electrodes surface. A higher amount of functional groups leads to a larger amount of passive products during cycling. The two strongly oxidized carbons ( $\mathrm{N}-\mathrm{HC}$ and $\mathrm{H} 2 \mathrm{SO} 4-\mathrm{HC})$ display a faster degradation over cycling, however, the capacitance of the other samples remain rather stable over 10,000 cycles. This indicates that only a large number of functional groups have strong impact on the capacitance. The material oxidized by $\mathrm{H}_{2} \mathrm{O}_{2}$ shows good capacitance retention and as well lower potential shift compared to the unmodified and reduced materials.

Influence of functional groups on the EIS.-EIS can give further understanding on the influence of functional groups on the evolution of the resistances. For this purpose, EIS were recorded during the previously discussed floating experiment. For sake of simplicity, only the most representative data are here reported, specifically a comparison between the oxidized carbon (H2O2-HC) in LP30 and LiTFSI-based electrolyte and two representative samples in LP30 (Figure 7). Except for the N-HC in LP30, all fresh cells show a Nyquist plot typical for double layer capacitor. Here, the main features are: a small semicircle at high frequencies, due to contact resistance among the particles and the particles-current collector, a slope at medium-to-low frequencies, indicating the pore resistance and, finally, a quasi-vertical line at low frequencies, related to the double layer capacitance. As concerning the N-HC, the branch at low frequencies sensibly departs from $90^{\circ}$, indicating a hindrance in the diffusion of the ions into the deeper and smaller pores. This feature was expected for the more oxidized 

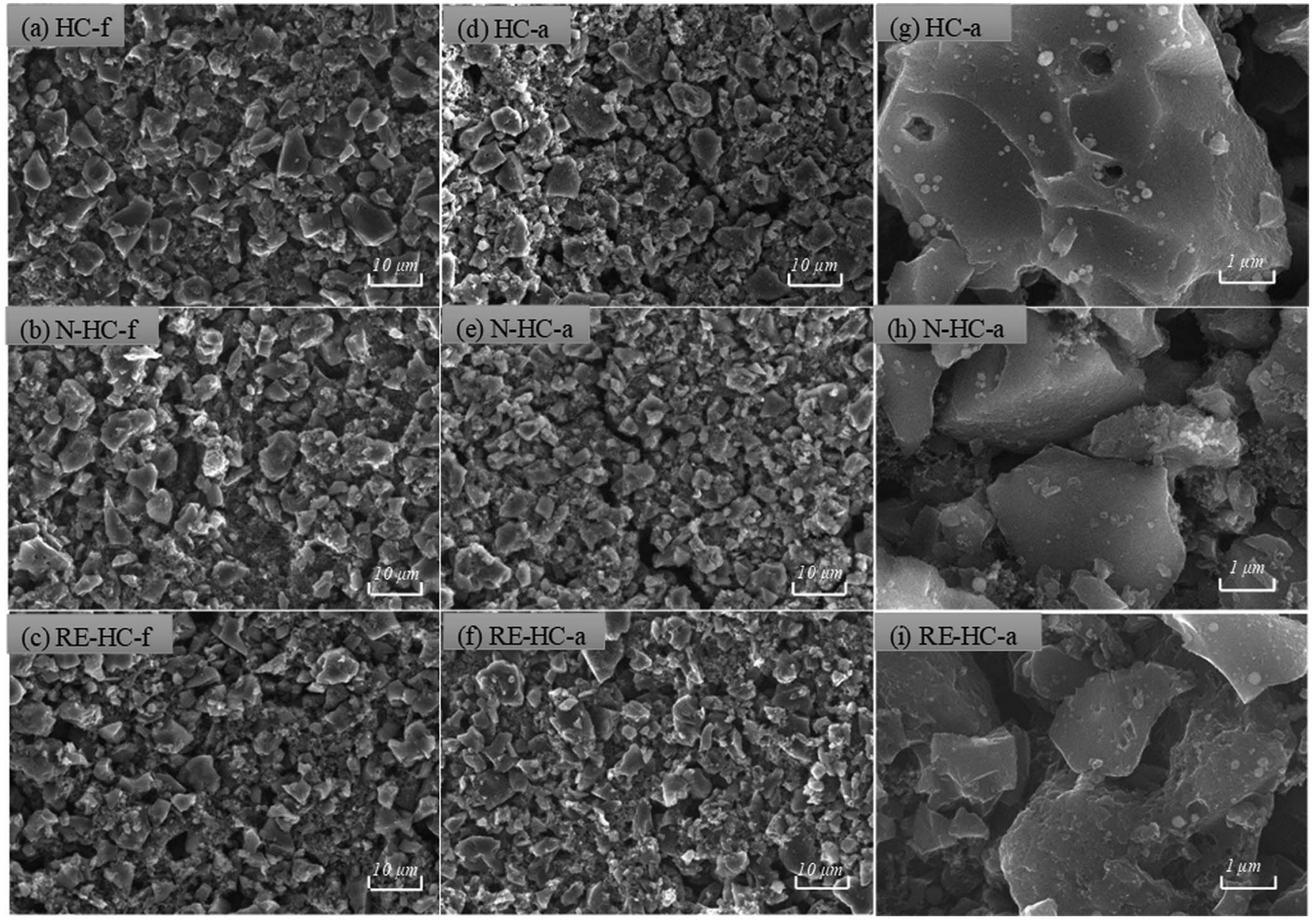

Figure 8. SEM images of fresh electrodes (HC-f, N-HC-f and RE-HC-f) and positive electrodes (HC-a, N-HC-a and RE-HC-a) after floating test in LP30.

material, where the flow of the ions in the pores can be partially hindered by the functional groups. Moreover, the equivalent series resistance (ESR), given by the intercept with the real axis, can give indications about the electronic conductivity of the different AC electrodes. The slight differences in ESR $(<1 \mathrm{ohm})$ among the fresh samples is inside the error of the measurements (due to other cell components and cable connections), indicating that the AC materials have similar electronic conductivity. This can be further confirmed by the Raman spectroscopy (Figure 2c), which proves that all samples have a similar graphitization degree. All spectra change with the progression of floating time. However, clear different features can be recognized on the Nyquist plots of capacitors floated in LiTFSI, respect to the ones aged in $\mathrm{LiPF}_{6}$-based electrolyte.

In LiTFSI-based electrolyte, the ESR and the semicircles at high frequencies increases very slightly, indicating that the contact resistance, the surface film (solid permeable interphase, SPI) and the conductivity of the electrolyte do not change significantly. On the other hand, the features at medium-to-low frequencies drastically change. After $150 \mathrm{~h}$ of floating, the pore-diffusion related slope extends to lower frequencies and is even replaced by a semi-circular shape, indicating a rise and overlapping of charge transfer resistance and pore diffusion. At low frequencies, the increase of the imaginary part of the impedance reflects the reduced capacitance with floating time (in agreement with Figure 5d). At the same time, the slope at low frequencies departs from the ideality, suggesting the progressive blockage of the pores, which inhibits the ideal capacitive behavior.

On the other side, the impedance evolution of the capacitors in LP30 is totally different (Figures 7b-7d). Here, the main changes with the floating time are occurring at high frequencies. The size of the high-frequency semicircle increases, indicating a rise of contact and SPI resistances. This feature changes more drastically for the strongly oxidized sample (N-HC) respect to unmodified one (HC). The decomposition products induced by the functional groups are accumulating on the external surface of the activated carbon, increasing the contact and SPI resistances. However, differently than in LiTFSI, in LP30 the evolution of the feature at middle-to-low frequencies is not observed, suggesting a different mechanism induced by the decomposition of the salt. The decrease of the low frequency imaginary impedance during floating indicates that the overall capacitance raises with time, which is consistent with the values obtained by the galvanostatic cycles (Figure 5a).

The sample oxidized with $\mathrm{H}_{2} \mathrm{O}_{2}(\mathrm{H} 2 \mathrm{O} 2-\mathrm{HC})$ shows similar (in LP30) or even better (in LiTFSI) performance respect to the unmodified HC. By considering these results together with the stability and capacitance behavior, this material seems the most promising one to be applied in $\mathrm{Li}$-ion capacitors.

Post-mortem analysis on aged electrodes.-Figure 8 displays the morphology of fresh (HC-f, N-HC-f and RE-HC-f) and aged positive electrodes (HC-a, N-HC-a and RE-HC-a) after the floating test. Some cracks are visible on the surface of aged electrodes based on $\mathrm{HC}$ and $\mathrm{N}-\mathrm{HC}$ (Figures 8d and 8e). This confirms the contact issues among the particles of oxidized samples after ageing. The images of aged electrodes shown in Figures 8g, 8h and 8i reveal light shadows particles present on the surface of $\mathrm{AC}$, which can be considered as polymeric products. This feature is not observed on fresh electrodes. The other two oxidized samples (H2SO4-HC and $\mathrm{H} 2 \mathrm{O} 2-\mathrm{HC}$, not shown here for sake of brevity) shows similar features. 


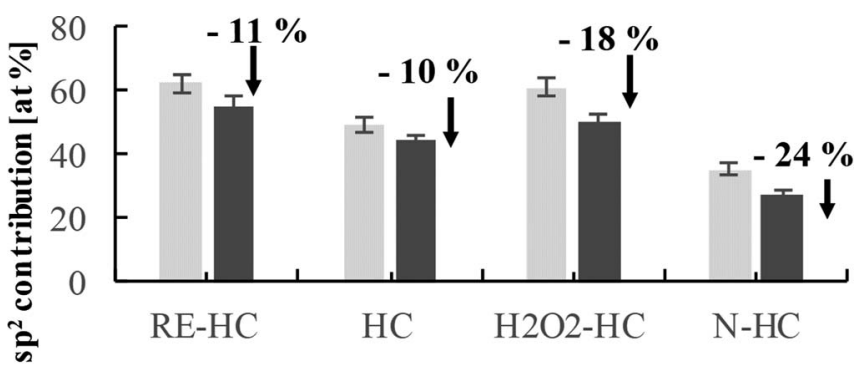

fresh 1 cycled

Figure 9. $\mathrm{sp}^{2}$ carbon contribution on the surface of the fresh and aged positive electrodes.

The graph in Figure 9 reports the change of the content of $\mathrm{sp}^{2}$ carbons on fresh and aged electrodes. A significant decrease of the contribution of the $\mathrm{sp}^{2}$ signal in the $\mathrm{C} 1 \mathrm{~s}$ XP spectrum can be observed on the surface of the aged oxidized samples. The decrease of this signal for $\mathrm{H} 2 \mathrm{O} 2-\mathrm{HC}$ and $\mathrm{N}-\mathrm{HC}$ is more pronounced than that for RE$\mathrm{HC}$ and $\mathrm{HC}$, which gives a hint of the thickness of the passive layer as well. Namely, the layer is thicker in the case of the oxidized samples. This can be correlated with the excellent stability of functionalized electrodes at high potential.

\section{Conclusions}

The removal of functional groups through reduction in $\mathrm{Ar} / \mathrm{H}_{2}$ atmosphere (RE-HC) confers to the AC the smallest ESW, resulting in lower energy and power densities. The AC with the largest amount of functionalities $(\mathrm{N}-\mathrm{HC})$ has the smallest anodic ESW. The other samples have the widest ESWs (2.8 V HC and H2O2-HC; $2.9 \mathrm{~V} \mathrm{H2SO} 4-\mathrm{HC}$ ). This means that the appropriate amount of functional groups (as the amount present in $\mathrm{HC}, \mathrm{H} 2 \mathrm{O} 2-\mathrm{HC}$ and $\mathrm{H} 2 \mathrm{SO} 4-\mathrm{HC}$ ) can make the electrodes stable in the $\mathrm{Li}$-salt containing electrolyte, with wide operation voltage window.

The surface functional groups on $\mathrm{AC}$ can restrain the potential shift with time in Li-salt containing electrolytes, not only in static condition (OCV), but also under dynamic condition (under polarization). The potential of the AC with the fewest functional groups (RE-HC) shifts rapidly in both conditions. This can be attributed to the higher amount of reactive sites on the surface of RE-HC, which are not stable in the electrolyte. $\mathrm{H} 2 \mathrm{O} 2-\mathrm{HC}$ is the most stable sample in static condition and has a better behavior respect to the unmodified $\mathrm{HC}$ in the dynamic situation. However, the capacitance evolution upon ageing, depends not only on the functional groups, but also on their interaction with the different Li-salt containing electrolytes. Indeed, in LiTFSI-based electrolyte, functional groups can infer a fast capacitance fading due to irreversible redox products, which hinder the movement of $\mathrm{TFSI}^{-}$in the pores. In this electrolyte, a higher amount of functional groups induces a faster capacitance decay. In LP30, the strongly oxidized sample (N$\mathrm{HC}$ ) shows a dramatic capacitance fade during ageing. However, the intermediate oxidized AC (the $\mathrm{H} 2 \mathrm{O} 2-\mathrm{HC}$ ) shows higher capacitance than that of $\mathrm{HC}$ during ageing. Moreover, during the whole ageing process, the stability of $\mathrm{H} 2 \mathrm{O} 2-\mathrm{HC}$ is comparable to the unmodified carbon $(\mathrm{HC})$. No capacitance fade is observed during the whole testing time. The contact resistance among the particles increase with the amount of functional groups during ageing: $\mathrm{N}-\mathrm{HC}$ shows the biggest increase during ageing.

In summary, the intermediate oxidation $\left(\mathrm{H}_{2} \mathrm{O}_{2}\right.$-treatment) introduces the most appropriate amount of functional groups. This modified AC is more stable under ageing test compared to the commercial AC and the AC with lower amount of functional groups (RE-HC).

Thanks to the small influence of functional groups on the cathodic ESW, the strongly oxidized $\mathrm{AC}(\mathrm{N}-\mathrm{HC})$ can be proposed as negative electrodes in EDLCs. However, contact problems among the particles could be a baffle for the real development of a hybrid system. The electrochemical behavior of composite electrodes with Li-insertion materials and $\mathrm{AC}$ with functional groups deserves to be further investigated. In addition, the effect of heteroatoms (like Nitrogen) on the capacitance and stability of supercapacitors is still not clear in organic electrolytes. At last but not least, through the mass balancing methods and using various combination of negative and positive carbon electrodes, the cell voltage can be widened and the cell capacitance properly optimized.

\section{Acknowledgments}

The authors gratefully acknowledge the financial support of the Ministry of Science, Research and Art (MWK) Baden-Württemberg through the Brigitte-Schlieben-Lange-Programm. The authors also acknowledge the technical supports from Bettina Hunzinger (SEM measurement) and Lihua Zhu (Raman measurements). This work contributes to the research performed at CELEST (Center for Electrochemical Energy Storage Ulm-Karlsruhe).

\section{ORCID}

Sonia Dsoke (1D https://orcid.org/0000-0001-9295-2110

\section{References}

1. L. H. Saw, Y. Ye, and A. A. Tay, Journal of Cleaner Production, 113 (2016).

2. Z. Rao, S. Wang, and G. Zhang, Energy Conversion and Management, 12, 52 (2011).

3. M. A. Hannan, M. H. Lipu, A. Hussain, and A. Mohamed, Renewable and Sustainable Energy Reviews, 78 (2017).

4. D. Cericola and R. Kötz, Electrochimica Acta, 72 (2012).

5. N. Ando, K. Kojima, S. Tasaki, H. Taguchi, K. Matsui, A. Shirakami, and Y. Hato, Lithium ion capacitor. 2012, Google Patents.

6. J. E. C. Japan, http://www.jmenergy.co.jp/en/index.html

7. F. Béguin, V. Presser, A. Balducci, and E. Frackowiak, Advanced materials, 14, 26 (2014).

8. D. Cericola, P. W. Ruch, R. Kötz, P. Novák, and A. Wokaun, Electrochemistry Communications, 6, 12 (2010).

9. A. Laheäär, A. Jänes, and E. Lust, Electrochimica Acta, 25, 56 (2011).

10. D. Stępień, Z. Zhao, and S. Dsoke, Journal of The Electrochemical Society, 11, 165 (2018).

11. K. Edström, T. Gustafsson, and J. Thomas, The cathode-electrolyte interface in a Li-ion battery, in Lithium-ion Batteries: Solid-electrolyte Interphase, 2004, World Scientific. p. 337.

12. T. Zhang, B. Fuchs, M. Secchiaroli, M. Wohlfahrt-Mehrens, and S. Dsoke, Electrochimica Acta, 218 (2016).

13. M. Tokita, N. Yoshimoto, K. Fujii, and M. Morita, Electrochimica Acta, 209 (2016)

14. Q. D. Nguyen, Y.-H. Wu, T.-Y. Wu, M.-J. Deng, C.-H. Yang, and J.-K. Chang, Electrochimica Acta, 222 (2016).

15. P. J. Hall, M. Mirzaeian, S. I. Fletcher, F. B. Sillars, A. J. Rennie, G. O. Shitta-Bey, G. Wilson, A. Cruden, and R. Carter, Energy \& Environmental Science, 9, 3 (2010).

16. C. Liu, B. B. Koyyalamudi, L. Li, S. Emani, C. Wang, and L. L. Shaw, Carbon, 109 (2016).

17. P. Simon and A. Burke, The electrochemical society interface, 1, 17 (2008).

18. S. S. Zhang, Journal of Solid State Electrochemistry, 7, 21 (2017).

19. M. Widmaier, B. Krüner, N. Jäckel, M. Aslan, S. Fleischmann, C. Engel, and V. Presser, Journal of The Electrochemical Society, 14, 163 (2016).

20. Y. Zhang, X. Li, J. Huang, W. Xing, and Z. Yan, Nanoscale research letters, 1, 11 (2016).

21. K. L. Parry, A. Shard, R. Short, R. White, J. Whittle, and A. Wright, Surface and Interface Analysis: An International Journal devoted to the development and application of techniques for the analysis of surfaces, interfaces and thin films, 11, 38 (2006).

22. J. H. Scofield, Journal of Electron Spectroscopy and Related Phenomena, 2, 8 (1976).

23. H. Y. Tran, M. Wohlfahrt-Mehrens, and S. Dsoke, Journal of Power Sources, 342 (2017).

24. K. Furukawa, N. Yoshimoto, M. Egashira, and M. Morita, Electrochimica Acta, 140 (2014).

25. M. Dahbi, F. Ghamouss, F. Tran-Van, D. Lemordant, and M. Anouti, Journal of Power Sources, 22, 196 (2011).

26. K. Xu, S. P. Ding, and T. R. Jow, Journal of The Electrochemical Society, 11, 146 (1999).

27. D. Weingarth, H. Noh, A. Foelske-Schmitz, A. Wokaun, and R. Kötz, Electrochimica Acta, 103 (2013).

28. K. S. Sing, Pure and applied chemistry, 4, 57 (1985). 
29. C. Largeot, C. Portet, J. Chmiola, P.-L. Taberna, Y. Gogotsi, and P. Simon, Journal of the American Chemical Society, 9,130 (2008).

30. R. Blume, D. Rosenthal, J. P. Tessonnier, H. Li, A. Knop-Gericke, and R. Schlögl, ChemCatChem, 18, 7 (2015).

31. F. Behboodi-Sadabad, H. Zhang, V. Trouillet, A. Welle, N. Plumeré, and P. A. Levkin, Advanced Functional Materials, 22, 27 (2017).

32. N. Zydziak, C. Hübner, M. Bruns, and C. Barner-Kowollik, Macromolecules, 9, 44 (2011)
33. J. A. Menéndez, B. Xia, J. Phillips, and L. R. Radovic, Langmuir, 13, 13 (1997).

34. H. Yang, K. Kwon, T. M. Devine, and J. W. Evans, Journal of The Electrochemical Society, 12, 147 (2000)

35. M. Morita, T. Shibata, N. Yoshimoto, and M. Ishikawa, Journal of power sources, 119 (2003).

36. S. Dsoke, B. Fuchs, E. Gucciardi, and M. Wohlfahrt-Mehrens, Journal of Power Sources, $282(2015)$. 